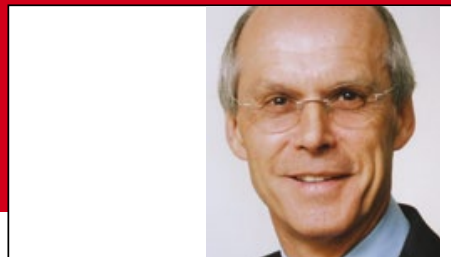

Prof. Dr. med. H. S. FüeßI

Isar-Amper-

Klinikum,

KI. München-Ost,

Haar

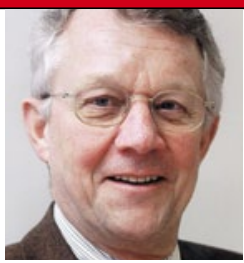

Prof. Dr. med. H. Holzgreve

Internist,

Kardiologische

Praxis, München

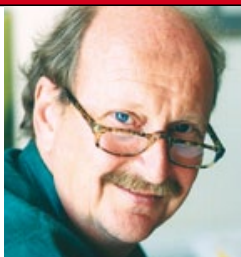

Prof. Dr. med.

\section{E. Ernst}

Peninsular

Medical School,

University

of Exeter/UK

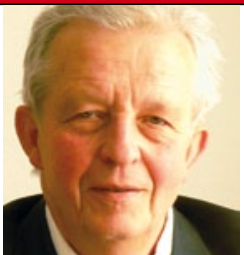

Prof. Dr. med.

K. Malberg

Immunologie,

Dresden-

Loschwitz

\title{
Schlaganfall- und Embolierisiko bei latentem Vorhofflimmern
}

Bei jedem vierten Schlaganfall sucht man vergeblich nach einer Ursache. Wahrscheinlich ist in vielen Fällen ein nicht bekanntes bzw. subklinisches Vorhofflimmern verantwortlich.

- Herzschrittmacher und implantierbare Defibrillatoren können supraventrikuläre Tachykardien entdecken und dokumentieren. Wird ein Vorhofflimmern bei Patienten gefunden, bei denen diese Rhythmusstörung zuvor noch nie elektrokardiografisch registriert wurde und die noch nie entsprechende Symptome hatten, spricht man von subklinischem Vorhofflimmern. Die Autoren haben nun bei 2580 Patienten mit neu implantierten Herzschrittmachern und Defibrillatoren drei Monate lang nach Episoden von supraventrikulären Tachykardien mit einer Frequenz über 190/min und einer Dauer von mehr als sechs Minuten gesucht. Bei den mindestens 65 Jahre alten Patienten mit Hypertonie war bislang kein Vorhofflimmern bekannt gewesen.

Innerhalb der ersten drei Monate trat bei $261(10,1 \%)$, in den folgenden 2,5 Jahren bei weiteren $633(24,5 \%) \mathrm{Pa}$ tienten ein derartiges subklinisches Vorhofflimmern - in der Regel jeweils meh- rere Perioden - auf. In den folgenden 2,5 Jahren manifestierte sich bei Patienten mit atrialen Tachykardien in den ersten drei Monaten Vorhofflimmern klinisch und elektrokardiografisch häufiger $(15,7 \%)$, gleichzeitig waren auch Schlaganfälle und Embolien zahlreicher $(4,2 \%)$ als bei den Patienten ohne solche Arrhythmien (3,1 bzw. 1,7 \%).

\section{- J. S. Healey et al. \\ Subclinical atrial fibrillation and the risk of stroke. New Engl. J. Med. 366 (2012) 120-129}

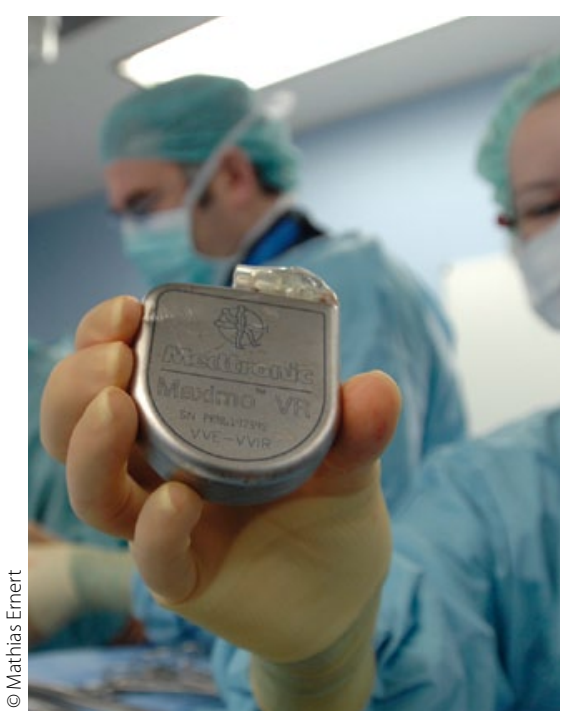

\section{Kommentar}

Moderne Herzschrittmacher und Defibrillatoren kann man als permanente kardiale Monitoren nutzen. So kann man als Nebenbefund nach deren Implantation bei einem nennenswerten Teil der Träger Vorhofflimmern diagnostizieren, das ohne diese Technik nicht entdeckt worden wäre. Diese latenten, subklinischen Tachyarrhythmien beinhalten ebenso wie ein klinisch manifestes Vorhofflimmern ein erhöhtes Schlaganfall- und Embolierisiko. Es gilt das bekannte Risikomuster: Je länger die Arrhythmieperioden dauern und je höher der $\mathrm{CHADS}_{2}$-Score ist, umso häufiger sind Schlaganfälle und Thromboembolien. Die Studie verdeutlicht ein Problem: Auch paroxysmales, asymptomatisches Vorhofflimmern, das mit konventionellen Methoden nicht zuverlässig diagnostiziert werden kann, ist ein Schlaganfall- und Embolierisiko.

H. HOLZGREVE .

Herzschrittmacher und implantierbare Defibrillatoren können subklinisches Vorhofflimmern dokumentieren. 